\title{
Antioxidant Activity and Phytochemical Content of Fresh and Freeze-Dried Lepisanthes fruticosa Fruits at Different Maturity Stages
}

\author{
Mirfat Ahmad Hasan Salahuddin ${ }^{1}$, Zaulia Othman ${ }^{2}$, Joanna Cho Lee Ying ${ }^{2}$, Erny Sabrina Mohd Noor ${ }^{1}$ \\ \& Salma Idris $^{3}$ \\ ${ }^{1}$ Agrobiodiversity and Environment Research Centre, MARDI Headquarters, Selangor, Malaysia \\ ${ }^{2}$ Horticultural Research Centre, MARDI Headquarters, Selangor, Malaysia \\ ${ }^{3}$ Seed and Genebank Centre, MARDI Headquarters, Selangor, Malaysia \\ Correspondence: Mirfat Ahmad Hasan Salahuddin, Agrobiodiversity and Environment Research Centre, \\ Malaysian Agricultural Research and Development Institute (MARDI) Headquarters, Persiaran MARDI-UPM, \\ 43400 Serdang, Selangor, Malaysia. Tel: 603-8953-6311. E-mail: mirfat@mardi.gov.my
}

Received: November 15, 2016

doi:10.5539/jas.v9n2p147
Accepted: December 19, 2016 Online Published: January 15, 2017

URL: http://dx.doi.org/10.5539/jas.v9n2p147

\begin{abstract}
Antioxidant and phytochemical compounds of fruits can vary widely depending on many factors such as processing and maturity stage as one of the major contributors. Therefore, this study investigated the antioxidant activity and phytochemical attributes of fresh and freeze-dried Lepisanthes fruticosa fruit extracts at eight different maturity stages. The freeze-dried extracts were obtained by lyophilisation using a freeze-dryer. In general, antioxidant activity and phytochemical contents of both fresh (FLF) and freeze-dried (FDLF) extracts showed a decrease with fruit maturation. Among the eight maturity stages developed for $L$. fruticosa, the lower maturity (unripe) stages exhibited the strongest potential, with stage 1 being the most notable. The FDLF fruit extracts were found to be significantly $(\mathrm{P}<0.05)$ stronger radical scavenger than FLF extracts at all maturity stages tested. The $\mathrm{IC}_{50}$ values of FDLF for the eight maturity stages were more effective, with stage 1 showing the lowest $\mathrm{IC}_{50}(1.57 \mathrm{mg} / \mathrm{ml})$. Total phenolic content of FDLF was also significantly $(\mathrm{P}<0.05)$ higher than FLF at all eight stages tested, with the highest also being shown at stage $1(15848.96 \pm 401.82 \mathrm{mg} / 100 \mathrm{~g})$. On the contrary, FLF extracts displayed significantly $(\mathrm{P}<0.05)$ higher total flavonoid content than FDLF at almost all stages except for 2, 3 and 6 . The highest content was shown in stage 1 with $37.35 \pm 0.77 \mathrm{mg} / 100 \mathrm{~g}$. These findings showed that antioxidant activity and phytochemical content of L. fruticosa fruits were significantly affected by processing and maturity. The obtained results are important for the promotion of use of $L$. fruticosa fruit extracts as a natural antioxidant in functional food production in the future.
\end{abstract}

Keywords: Lepisanthes fruticosa, freeze-drying, radical scavenging activity, total phenolic, total flavonoid

\section{Introduction}

Lepisanthes fruticosa (Roxb) Leenh or locally known as ceri Terengganu is a non-seasonal underutilised fruit species that produces fruits throughout the year (Mirfat \& Salma, 2015). It belongs to the family Sapindaceae and can be found in South East Asia which comprise Malaysia, Myanmar, Indo-China, Thailand, Philippines and Indonesia (Lim, 2013). The species is found growing naturally in the forests and only occasionally cultivated. In Malaysia, this species is widely distributed in Johor and the East Coast of Peninsular Malaysia (Mirfat \& Salma, 2015). A number of species from the genus Lepisanthes are widely used in traditional and folk medicine systems in different parts of the world (Kuspradini, Ritmaleni, \& Mitsunaga, 2012). Based on the ethnobotanical studies, L. fruticosa is usually consumed as food source and also used in traditional medicine by rural folks. The seed is eaten roasted and the root is used in a compound poultice to relieve itching and to lower temperature during fever (Mirfat \& Salma, 2015). Wetwitayaklung, Charoenteeraboon, Limmatvapirat, and Phaechamud (2012) have reported that $L$. fruticosa root has antipyretic properties and the ripe fruit has antidiarrhoea properties.

Recently, interest in L. fruticosa fruits has arisen due to its strong antioxidant capacity as compared to a numbers of underutilised fruits and commercial fruits (Mirfat \& Salma, 2015). Our earlier study also revealed that $L$. fruticosa ripe fruits showed the highest free radical scavenging activity and had a great source of total phenolic contents among many other fruits tested (Mirfat \& Salma, 2015). Phenolics are one of the major phytochemicals 
that play vital roles in the inhibition of free radicals to prevent or slow the oxidative damage in our body (Mirfat, Salma, Razali, \& Umi Kalsum, 2015). However, it is interesting to note that antioxidant and phytochemical compounds of fruits can vary widely depending on many factors such as processing and maturity stage as one of the major contributors.

To the best of our knowledge, antioxidant and phytochemical content of L. fruticosa fruits at different maturity stages have never been compared and evaluated. Maturity is one of the factors which can strongly influence the nutritional value as well as physiological properties such as developmental of colours and texture of fruits (Mohd. Zainudin, Abdul Hamid, Anwar, Osman, \& Saari, 2014). Previous reports also stated that changes in antioxidant properties were found to be varied different fruits such as olive, orange and tomato (Mohd. Zainudin et al., 2014). Changes of the antioxidant and phytochemical compounds during maturation hold great significance from both dietary and nutritional point of view. There is a great importance to identify the harvest maturity with enhanced levels of antioxidant activity and phytochemical compounds targeting increased functional properties $(\mathrm{Fu}, \mathrm{He}$, Zhao, Yang, \& Mao, 2009).

In order to meet different requirements of consumers and preserve fresh plant materials, fruits could also be processed. One of the widely used processing method of fruits is freeze-drying. It was suggested that dried fruits showed higher antioxidant activity and polyphenolic content than fresh fruits due to their low moisture content with increased shelf life (Vijaya Kumar Reddy, Sreeramulu, \& Raghunath, 2010).

Therefore, this study was carried out with the objective of evaluating the antioxidant activity and phytochemical content of fresh and freeze dried L. fruticosa fruits at different maturity stages in order to come up with the best harvesting maturity. The fruit processing can be explored as a viable method for processing fruits retaining the maximum amount of these antioxidants.

\section{Methods}

\subsection{Plant Materials}

Lepisanthes fruticosa fruits were sampled from MARDI fruit genebank in Serdang, Selangor. The flowers of $L$. fruticosa were tagged initially after fully bloom and let to grow until full maturity. The fruits were harvested manually every week after tagging (Figure 1) to evaluate the characteristics, colour and shape of fruits. After evaluating three cycles of the fruit development, colour indices were developed.

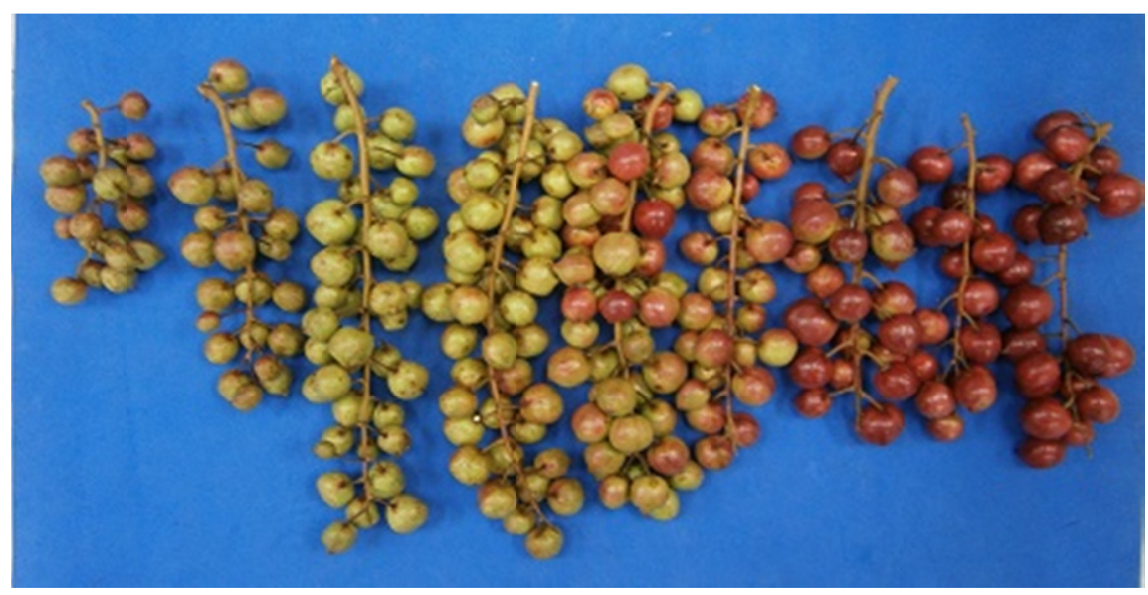

Figure 1. Different colour indices of L. fruticosa during fruit development

\subsection{Sample Preparation and Extraction}

Fruit samples were washed with running tap water before being weighed for the edible portion parts. For the freeze-dried samples, the samples were transferred into freeze dryer bottle in and kept at $-80{ }^{\circ} \mathrm{C}$ freezer overnight. Then, the frozen samples were lyophilised at $-85^{\circ} \mathrm{C}$, pressure 250 mtorr for 3 days using a bench-top freeze dryer (Virtis, USA). The freeze-dried samples were finely ground and kept in an airtight container prior to extraction. The fresh and the freeze-dried samples were then extracted using methanol (1:10) and shaken for approximately 1 hour. The extracts were then centrifuged for 10 minutes at 10,000 rpm. The residue was 
separated from the supernatant and the procedure was repeated twice. The two resulting supernatants were mixed together to obtain the crude extracts which were stored at $-80^{\circ} \mathrm{C}$ prior to analysis.

\subsection{Determination of Antioxidant Activity}

Scavenging activity of the fruit extracts on 2,2-diphenyl-1-picrylhydrazyl (DPPH) radicals was assayed according to Molyneux (2004) with some modifications. Various concentrations of the crude extracts in methanol were prepared to give a final volume of $7 \mu 1$ and were mixed with $280 \mu 1$ of methanolic solution containing DPPH (Sigma, USA) radicals resulting in a final concentration of $0.06 \mathrm{mM}$. The mixture was vigorously shaken and left to stand for $30 \mathrm{~min}$. in the dark. The absorbance was measured at $517 \mathrm{~nm}$ and ascorbic acid (Sigma, USA) was used as the positive control. The results were expressed as $\mathrm{IC}_{50}$ value $(\mathrm{mg} / \mathrm{ml})$, which is the inhibitory concentration at which DPPH radicals were scavenged by $50 \%$. All procedures were carefully carried out with minimum exposure of light.

\subsection{Determination of Total Phenolic Content}

Total phenolic content of the extracts was estimated by a colorimetric assay as described by Singleton and Rossi (1965) with some modifications. Briefly, $50 \mu \mathrm{l}$ of the crude extracts were mixed with $100 \mu 1$ of Folin Ciocalteau's phenol reagent (Merck, Germany). After 3 mins, $100 \mu$ l of $10 \%$ sodium carbonate $\left(\mathrm{Na}_{2} \mathrm{CO}_{3}\right)($ Sigma Aldrich, USA) was added to the reaction mixture and allowed to stand in the dark for 60 mins. The absorbance was measured at $725 \mathrm{~nm}$ and the total phenolic content was obtained from a calibration curve using gallic acid $(0-10 \mu \mathrm{g} / \mathrm{ml})$ as a standard reference. Estimation of the phenolic content was carried out in triplicate. The results were mean values \pm standard deviations and expressed as $\mathrm{mg}$ gallic acid per $100 \mathrm{~g}$ samples. All procedures were carefully carried out with minimum exposure of light.

\subsection{Determination of Total Flavonoid Content}

Measurement of flavonoid concentration of the extracts was based on the method described by D. Kim, Chun, Y. Kim, Moon, and Lee (2003) with some modifications. An aliquot of $100 \mu \mathrm{l}$ of fruit extract was diluted with 400 $\mu 1$ of distilled water. Afterwards, $30 \mu 1$ of $5 \%$ sodium nitrite $\left(\mathrm{NaNO}_{2}\right)$, (Sigma, USA) solution was added and allowed to react for $5 \mathrm{~min}$. Following this, $20 \mu \mathrm{l}$ of $10 \%$ aluminium chloride $\left(\mathrm{AlCl}_{3} \cdot 6 \mathrm{H}_{2} \mathrm{O}\right)$ (Sigma, USA) was added and left to stand for $5 \mathrm{~min}$. Finally, $200 \mu \mathrm{l}$ of sodium hydroxide $(\mathrm{NaOH})$ (Sigma, USA) was added and the mixture was well-mixed with a vortex. All samples were analyzed in triplicate and the absorbance was measured immediately at $510 \mathrm{~nm}$. Rutin (Sigma, USA) was used to calculate the standard curve and the results were expressed as mg rutin per $100 \mathrm{~g}$ samples.

\subsection{Statistical Analysis}

The results of this study are means and standard deviations of three measurements. Data were further analysed using SAS9.2 (32) statistical software and procedures.

\section{Results}

Maturity study showed that one cycle of $L$. fruticosa fruit development (from flowering to fully red skin colour) was about 5 weeks. Eight maturity indices were developed according to the progressive fruit development as indicated by the colour changes. Figure 2 shows all the maturity indices developed for $L$. fruticosa fruits based on the following criteria; 1 = fully green ( 2 weeks after flower bloom (FB)), $2=$ green with trace of light red (3 weeks after FB), $3=$ more green than light red in whole fruit (3-4 weeks after FB), $4=$ more light red than green ( 4 weeks after FB), $5=$ light red with trace of green ( $4-5$ weeks after FB), $6=$ light red with trace of bright red (5 weeks after FB), $7=$ bright red with trace of light red $(>5$ weeks after FB), $8=$ fully bright red ( $>5$ weeks after FB).

Results of the antioxidant activity of fresh and freeze dried $L$. fruticosa at eight different maturity stages are presented in Figure 3. From the results, the free radical scavenging activities of both $L$. fruticosa fruit extracts were observed to be increased with fruit maturation, indicating the decrease of antioxidant activity. The activity of freeze-dried L. fruticosa (FDLF) was significantly different $(\mathrm{P}<0.05)$ as compared to fresh (FLF) at all maturity stages tested. The lowest $\mathrm{IC}_{50}$ value was observed at stage 1 with a significant difference $(\mathrm{P}<0.05)$ between FDLF $(1.57 \pm 0.89 \mathrm{mg} / \mathrm{ml})$ and FLF $(3.04 \pm 1.05 \mathrm{mg} / \mathrm{ml})$. The $\mathrm{IC}_{50}$ values of FDLF for the eight maturity stages ranged from $1.57-6.51 \mathrm{mg} / \mathrm{ml}$. Lee et al. (2007) reported that $\mathrm{IC}_{50}$ values lower than $10 \mathrm{mg} / \mathrm{ml}$ are indicative of the effective antioxidant activity. However, there was no significance difference $(\mathrm{P}<0.05)$ shown among FDLF extracts when they compared to each other. Fresh extracts (FLF) was observed to show significance difference $(\mathrm{P}<0.05)$ only at stage $5,6,7,8$. 


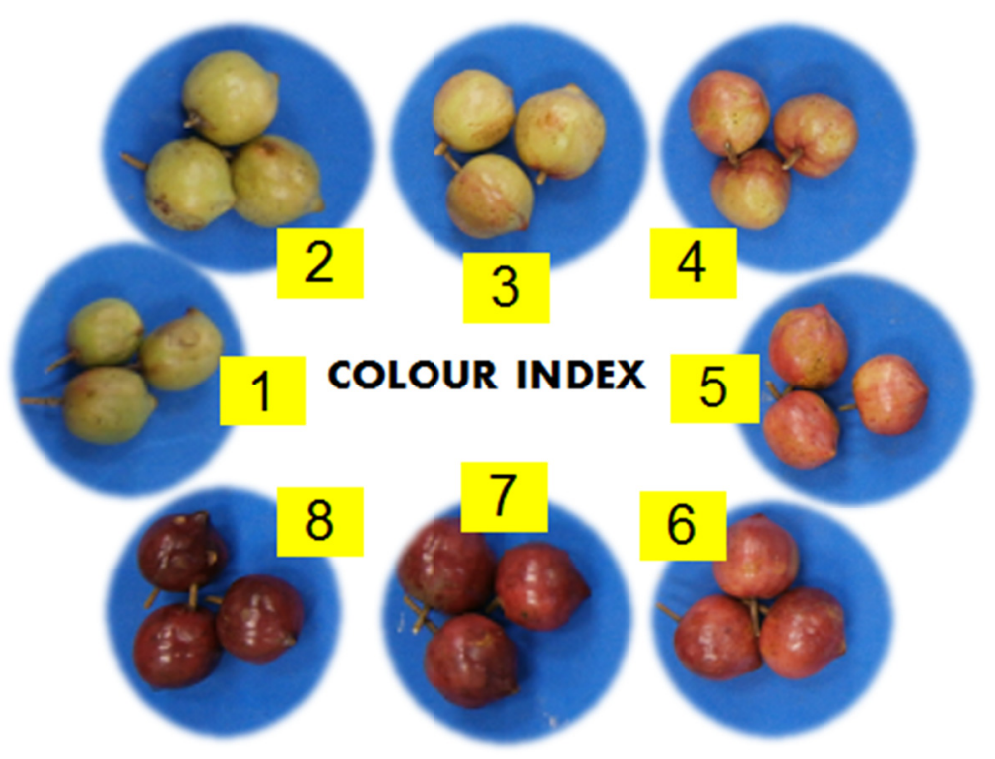

Figure 2. Lepisanthes fruticosa fruits at eight different maturity stages

Note. 1 = fully green, 2 = green with trace of light red, $3=$ more green than light red in whole fruit, $4=$ more light red than green, $5=$ light red with trace of green, $6=$ light red with trace of bright red, $7=$ bright red with trace of light red, 8 = fully bright red.

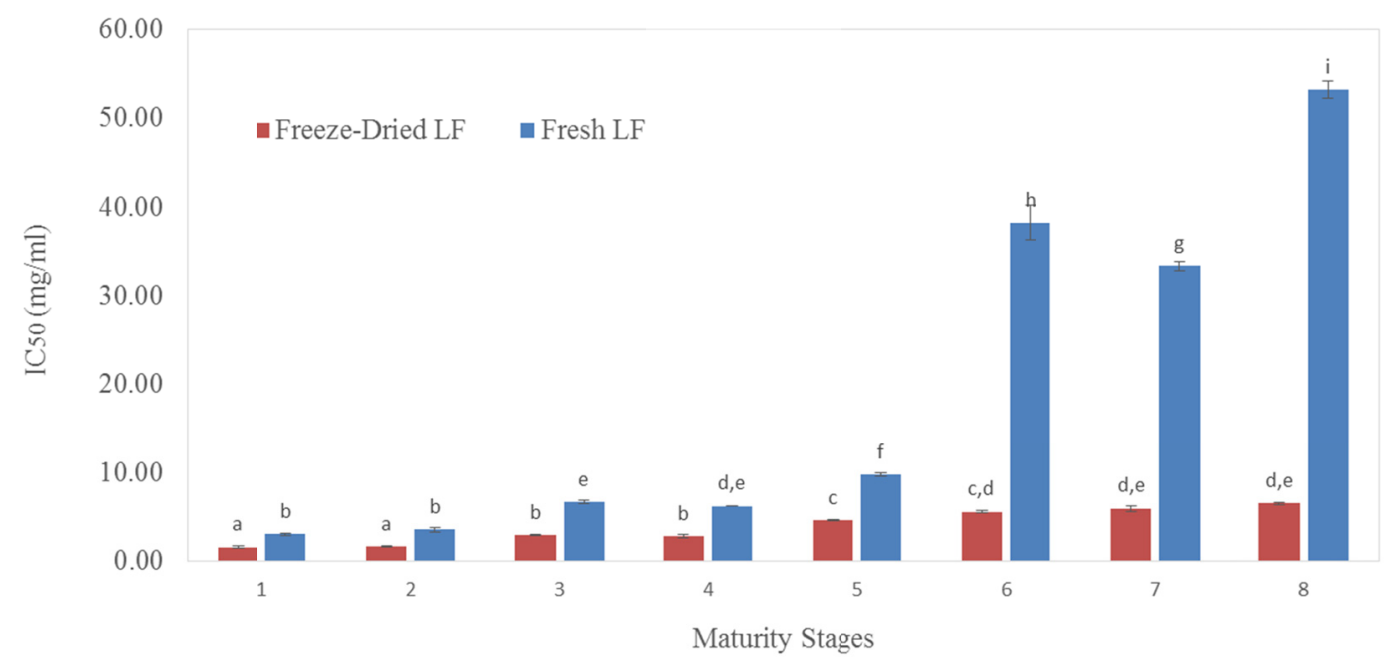

Figure 3. Antioxidant activity $\left(\mathrm{IC}_{50}\right)$ of freeze-dried and fresh L. fruticosa fruit extracts at eight maturity stages Note. Values marked with different letters are significantly different at $\mathrm{P}<0.05$. The higher the $\mathrm{IC}_{50}$ values indicate the stronger ability to act as radical scavengers. Data expressed as means \pm standard deviations $(\mathrm{n}=3)$.

Figure 4 shows the total phenolic content (TPC) of FDLF and FLF extracts at different maturity stages. Similar to antioxidant activity, total TPC of FDLF were significantly $(\mathrm{P}<0.05)$ higher than FLF at all eight stages tested. Total phenolic content of FDLF extracts ranged from $953.59-158848.96 \mathrm{mg} / 100 \mathrm{~g}$, with the highest being shown at stage $1(15848.96 \pm 401.82 \mathrm{mg} / 100 \mathrm{~g})$. The trend was also observed to be decreasing with fruit maturation. Of all the maturity stages, FDLF showed no significance difference $(\mathrm{P}<0.05)$ at stage 7 to 8 . Meanwhile, there was no significance difference observed for fresh at all maturity stages tested.

On the other hand, results of total flavonoid content (TFC) were on the contrary. From Figure 5, TFC of FLF extracts were significantly higher $(\mathrm{P}<0.05)$ than FDLF at almost all stages except for 2,3 and 6 . The highest TFC was observed at stage 1 with FLF and FDLF showed $37.35 \pm 0.77 \mathrm{mg} / 100 \mathrm{~g}$ and FD $32.53 \pm 1.32 \mathrm{mg} / 100 \mathrm{~g}$, respectively. FLF was found to be significantly varied $(\mathrm{P}<0.05)$ only at stage 1 and 6 , whereas FDLF showed 
significance at stage 1, 2 and 5. Similar to that shown by that TPC (Figure 4), TFC was also decreased as the fruits ripened at most of the maturity stages tested.

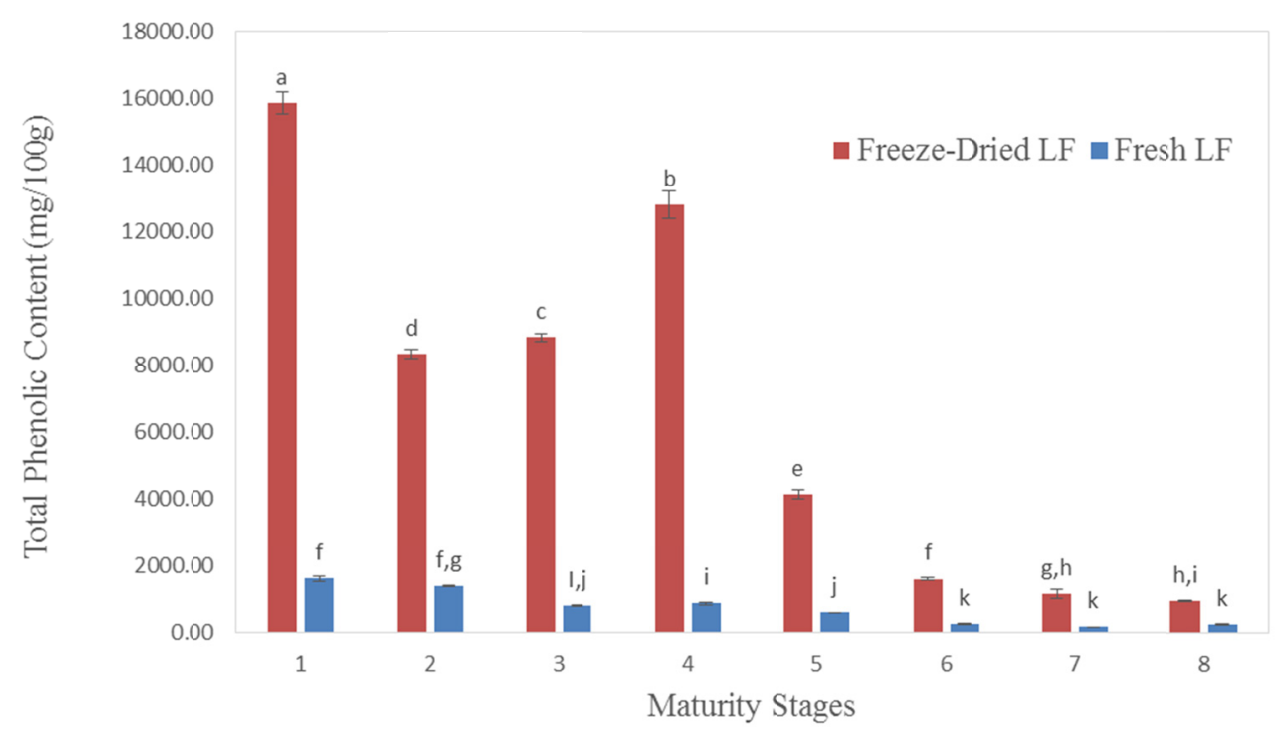

Figure 4. Total phenolic content of L. fruticosa fruit extracts at eight maturity stages; LF; Lepisanthes fruticosa Note. Values marked with different letters are significantly different at $\mathrm{P}<0.05$. Data expressed as means \pm standard deviations $(\mathrm{n}=3)$.

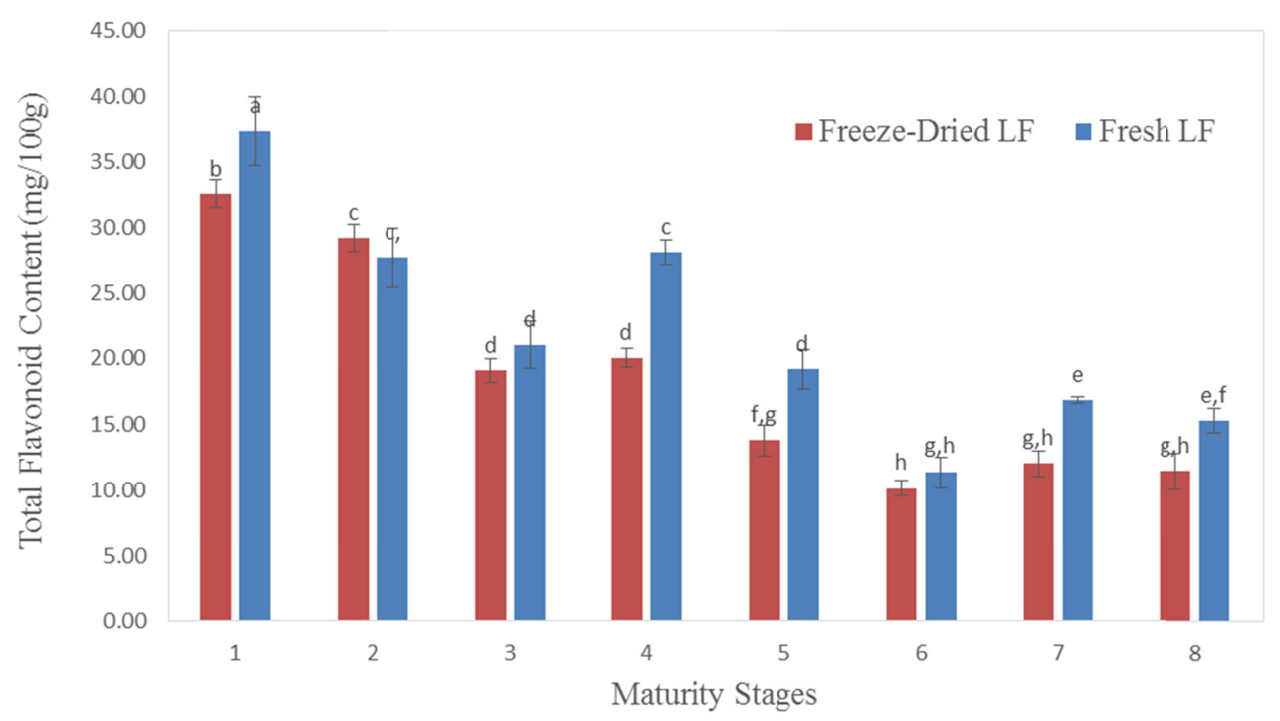

Figure 5. Total flavonoid content of L. fruticosa fruit extracts at eight maturity stages; LF; Lepisanthes fruticosa Note. Values marked with different letters are significantly different at $\mathrm{P}<0.05$. Data expressed as means \pm standard deviations $(\mathrm{n}=3)$.

\section{Discussion}

Phenolics and flavonoids are the main phytochemicals responsible for the antioxidant capacity of fruits. They are important for human health because of their activities as radical scavengers (Hertog, Hollman, \& Van de Putte, 1993). The findings have revealed that freeze drying could enhance the antioxidant activity and total phenolic content in L. frutiosa fruits, which is against the notion that processed food has lower antioxidant properties than 
the fresh ones. The FDLF extracts were found to be significantly $(\mathrm{P}<0.05)$ stronger radical scavenger than FLF at all maturity stages tested with all $\mathrm{IC}_{50}$ values of lower than $10 \mathrm{mg} / \mathrm{ml}$. This is in accordance to Lee et al. (2007) who reported that $\mathrm{IC}_{50}$ values lower than $10 \mathrm{mg} / \mathrm{ml}$ are indicative of the effective antioxidant activity. Freeze drying process has been popularly applied in laboratory practice and food industry to preserve fresh plant material. Freeze drying increases tissue porosity which results in higher extraction efficiency of antioxidants such as phenolic compounds. This in agreement with Materska (2004) that freeze drying of blackcurrants increased the total levels of phenolic compounds, and they attributed this to higher sample porosity and extraction efficiency of phenolic compounds from plant tissue. Other researcher reported that freeze drying protects materials containing heat-sensitive antioxidant compounds such as plant phenolics (Norshahida et al., 2011). Chang, Lin, Chang, and Liu (2006) also reported that processed fruits contained higher nutritional values than the fresh ones. This is supported by their study on drying process of tomatoes which enhanced their nutritional values by increasing parts of the total phenolic and total flavonoid contents.

The present study has also shown that antioxidant activity and phytochemical contents of both FDLF and FLF extracts seemed to be decreased with fruit maturation. Therefore, it can be suggested that the lower the maturity index, the higher the antioxidant activity, total phenolic and total flavonoid contents. Among the eight maturity stages developed for L. fruticosa, the unripe green stages were the strongest antioxidants, while the red, well-matured stages, which are the ones usually consumed, were the weakest ones. Particularly, the youngest stage of $L$. fruticosa fruits, stage 1 for both FDLF and FLF extracts showed the strongest antioxidant potential.

The findings may suggest that maturation greatly affects the antioxidant activity and phytochemical contents of $L$. fruticosa, and this factor should be taken into consideration when evaluating the antioxidant potential of fruits. Studies have shown that there are significant differences in the content of bioactive compounds and antioxidant capacity of tropical fruits at various stages of ripening. Considering quantitative changes of total bioactive compounds, unripe fruits have been reported to have highest level of bioactivities, which decreased at the semi-mature stage and remained unchanged at the commercial harvest maturity (Mphahlele, Stander, Fawole, \& Opara, 2014). This is in accordance to Arancibia-Avila et al. (2008) that ripe durian had the highest antioxidant capacity and bioactive compounds. Total polyphenols and flavonoids in the ripe durian were higher than in mature and overripe. Other studies also showed that the unripe yellow fruits of the Greek Service Tree (Sorbus domestica) were the strongest antioxidants and had the highest phenolic contents, while the well matured brown fruits were the weakest ones and gave the lowest phenolic contents (Termentzi, Kefalas, \& Kokkalou, 2009). This is also the in agreement with Huseyin, Mustafa, Sedat, and Cemal (2008) that during maturation of cranberry, from green to dark red stage, the total phenolic content decreased from 7990 to $4745 \mathrm{mg} \mathrm{GAE} / \mathrm{kg} \mathrm{FW}$.

In conclusion, the study clearly showed that antioxidant activity and phytochemical content of $L$. fruticosa fruits were significantly affected by processing and maturity. The antioxidant activity and the naturally occurring antioxidant phtytochemicals, phenols and flavonoids reached their highest levels at the youngest stage as indicated by the lowest maturity stage. Freeze-dried extracts were identified as the most remarkable antioxidant with significantly $(\mathrm{P}<0.05)$ higher radical scavenging and total phenolic contents than fresh fruit extracts. Freeze drying can be explored as a viable method for processing fruits retaining the maximum amount of these antioxidant properties as all the freeze-dried extracts showed greater antioxidant capacity than fresh ones. These results may be useful for the promotion of use of $L$. fruticosa fruit extracts as a natural antioxidant in functional food production in the future.

\section{References}

Arancibia-Avila, P., Toledo, F., Yong, S. P., Soon, T. J., Seong, G. K., Buk, G. H., ... Gorinstein, S. (2008). Antioxidant properties of durian fruit as influenced by ripening. Food and Science Technology, 1-8. http://dx.doi.org/10.1016/j.1wt.2007.12.001

Chang, C. H., Lin, H. Y., Chang, C. Y., \& Liu, Y. C. (2006). Comparisons on the antioxidant properties of fresh, freeze-dried and hot-air-dried tomatoes. Journal of Food Engineering, 77, 478-485. http://dx.doi.org/10.1016/j.jfoodeng.2005.06.061

Fu, M., He, Z., Zhao, Y., Yang, J., \& Mao, L. (2009). Antioxidant properties and involved compounds of daylily flowers in relation to maturity. Food Chemistry, 114, 1192-1197. http://dx.doi.org/10.1016/ j.foodchem.2008.10.072

Hertog, M. G. L., Hollman, P. C. H., \& Van de Putte, B. (1993). Content of potentially anti-carcinogenic flavonoids of tea infusions, wines and fruit juices. Journal of Agricultural and Food Chemistry, 41, 1242-1246. http://dx.doi.org/10.1021/jf00032a015 
Huseyin, C., Mustafa, O., Sedat, S., \& Cemal, K. (2008). Phytochemical accumulation and antioxidant capacity at four maturity stages of cranberry fruit. Scientia Horticulturae, 117, 345-348. http://dx.doi.org/10.1016/ j.scienta.2008.05.005

Kim, D., Chun, O. Kim, Y., Moon, H., \& Lee, C. (2003). Quantification of phenolics and their antioxidant capacity in fresh plums. Journal of Agricultural and Food Chemistry, 51, 6509-6515. http://dx.doi.org/ $10.1021 / \mathrm{jf0} 0343074$

Kuspradini, H., Ritmaleni, D. S., \& Mitsunaga, T. (2012). Phytochemical and comparative study of anti-microbial activity of Lepisanthes amoena leaves extract. Journal of Biology, Agriculture and Healthcare, 2(11), 80-86.

Lee, Y. L., Tsung, Y. M., \& Mau, J. L. (2007). Antioxidant properties of various extracts from Hypsizigus marmoreus. Food Chemistry, 104, 1-9. http://dx.doi.org/10.1016/j.foodchem.2006.10.063

Lim, T. K. (2013). Edible Medicinal and Non-Medicinal Plants (Vol. 6, Fruits). Netherlands: Springer. http://dx.doi.org/10.1007/978-94-007-5628-1

Materska, M. (2014). Bioactive phenolics of fresh and freeze-dried sweet and semi-spicy pepper fruits (Capsicum annuum L.). Journal of Functional Foods, 7, 269-277. http://dx.doi.org/10.1016/j.jff.2014. 02.002

Mirfat, A. H. S., \& Salma, I. (September 2, 2015). Ceri Terengganu: The future antioxidant superstar. MARDI Scientia, 6, 6 .

Mirfat, A. H. S., Salma, I., Razali, M., \& Umi Kalsum, H. Z. (2015). Antioxidant and nutritional values of selected underutilised Mangifera species in Malaysia. Indian Journal of Plant Genetic Resources, 28(1), 72-79. http://dx.doi.org/10.5958/0976-1926.2015.00010.8

Mohd. Zainudin, M. A., Abdul Hamid, A., Anwar, F., Osman, A., \& Saari, N. (2014). Variation of bioactive compounds and antioxidant activities of carambola (Averrhoa carambola L.) at different ripening stages. Scientia Horticulturae, 172, 325-331. http://dx.doi.org/10.1016/j.scienta.2014.04.007

Molyneux, P. (2004). The use of the stable free radical diphenylpicryl-hydrazyl (DPPH) for estimating antioxidant activity. Songklanakarin Journal of Science and Technology, 26(2), 211-219.

Mphahlele, R. M., Stander, M. A., Fawole, O. A., \& Opara, U. L. (2014). Effect of fruit maturity and growing location on the postharvest contents of flavonoids, phenolic acids, vitamin $\mathrm{C}$ and antioxidant activity of Pomegranate juice (cv. Wonderful). Scientia Horticulturae, 179, 36-45. http://dx.doi.org/10.1016/ j.scienta.2014.09.007

Norshahida, M. S., Azizah, A. H., Azizah, O., Nazamid, S., Farooq, A., Mohd. Sabri, P. D., \& Muhammad Redzuan, H. (2011). Effect of freeze drying on the antioxidant compounds and antioxidant activity of selected tropical fruits. International Journal of Molecular Sciences, 12(7), 4678-4692. http://dx.doi.org/10.3390/ijms12074678

Singleton, V. L., \& Rossi, J. A. (1965). Colorimetry of total phenolics with phosphomolybdic-phosphotungstic acid reagents. American Journal of Enology and Viticulture, 16, 144-158.

Termentzi, A., Kefalas, P., \& Kokkalou, E. (2009). Antioxidant activities of various extracts and fractions of Sorbus domestica fruits at different maturity stages. Food Chemistry, 98, 599-608. http://dx.doi.org/10.1016/j.foodchem.2005.06.025

Vijaya Kumar Reddy, C., Sreeramulu, D., \& Raghunath, M. (2010). Antioxidant activity of fresh and dry fruits commonly consumed in India. Food Research International, 43, 285-288. http://dx.doi.org/10.1016/ j.foodres.2009.10.006

Wetwitayaklung, P., Charoenteeraboon, J., Limmatvapirat, C., \& Phaechamud, T. (2012). Antioxidant activities of some Thai and exotic fruits cultivated in Thailand. Research Journal of Pharmaceutical, Biological and Chemical Sciences, 3(1), 12-21.

\section{Copyrights}

Copyright for this article is retained by the author(s), with first publication rights granted to the journal.

This is an open-access article distributed under the terms and conditions of the Creative Commons Attribution license (http://creativecommons.org/licenses/by/4.0/). 